Article

\title{
Effects of Diaphorina citri Population Density on Daily Timing of Vibrational Communication Calls: Potential Benefits in Finding Forage
}

\author{
Richard W. Mankin ${ }^{1} * \mathbb{C}$, Rikin Patel ${ }^{2}$, Mason Grugnale ${ }^{1}$ and Ethan Jetter ${ }^{3}$ \\ 1 Center for Medical, Agricultural, and Veterinary Entomology, US Department of Agriculture, Gainesville, \\ FL 32608, USA; mgrugnale2113@gmail.com \\ 2 Department of Biology, University of Virginia, Charlottesville, VA 22904, USA; rap5hf@virginia.edu \\ 3 Department of Nutritional Sciences, University of Florida, Gainesville, FL 32611, USA; ejetter19@gmail.com \\ * Correspondence: Richard.Mankin@usda.gov; Tel.: +1-352-347-5774
}

Received: 18 February 2020; Accepted: 9 March 2020; Published: 13 March 2020

\begin{abstract}
Adult Diaphorina citri (ACP) use visual and chemical cues to locate young citrus flush shoots on which they forage and oviposit, and they use vibrational communication duetting calls as cues to help locate mates. For individual pairs, calling and mating usually peaks between 10:00 and 15:00. To explore whether call rates (calls/h) are affected by interactions with nearby conspecifics, rates were compared in small citrus trees on which either 5 or $25 \mathrm{ACP}$ female and male pairs had been released at 17:00 for later recording from sunrise (06:00) to 22:00. Final ACP locations were noted 40 $\mathrm{h}$ after release. Call rates were similar in both treatments during normal mating hours. However, rates were significantly higher for low- than high-density treatments between 06:00 and 10:00, which suggests calling during this period may be affected by conspecific density. Both sexes aggregated on flush at both densities. We discuss the potential that ACP producing calls near sunrise, outside of normal mating hours, might benefit from gains in reproductive fitness in low-density contexts if they call not only to locate mates but also to locate preferred flush-in which case, co-opting of vibrations to disrupt both mating and foraging may be feasible.
\end{abstract}

Keywords: mating behavior; citrus greening disease; aggregation

\section{Introduction}

Methods to co-opt forage- and mate-locating cues for management of the Asian citrus psyllid, Diaphorina citri Kuwayama (Hemiptera: Liviidae), are drawing increased focus to reduce its populations and its spread of the economically devastating huanglongbing disease in citrus groves [1,2]. Adults of both sexes locate host citrus trees through visual and olfactory cues [3] and have similar propensities to disperse onto new host trees when conspecific populations build up to levels that reduce reproductive fitness [4]. Once on the hosts, females seek young leaf-flush shoots [5] on which to feed and lay eggs, as nymphs are obligate flush feeders [6]. Adults and nymphs readily acquire the disease-causing bacteria from infected trees during feeding activity, and adults then transmit the bacteria to uninfected trees as they move about the grove [7].

The mechanisms by which $D$. citri locate flush shoots are not fully understood, but their positive phototropic behavior [8-10] assists in locating shoots on the outer branches, and the preference of females for young flush is known to be guided by assessments of tissue hardness [11,12] and chemical cues that vary with leaf age $[13,14]$. In addition, females are attracted to odors from feeding damage by conspecifics but, once on the tree, show preference for uninfested young flush in the presence of odors from feeding damage [15]. 
For mating, D. citri employ substrate-borne vibrational communication duets-during which a male first calls and then moves towards a replying female [16-18]. There is evidence that males are attracted to one or more cuticular hydrocarbons produced by females [19] and they may be stimulated to produce vibrational signals in the presence of female cuticular hydrocarbons [20]. Because males search for females with which to mate and also search for flush on which to feed, they often are found co-aggregated with females on young flush shoots [5,21].

Females have been observed to call in the absence of males, but the role of calls occurring outside of vibrational communication duets is not well understood [16,22]. Vibrational communication has also been employed by different hemipterans to locate food resources or protective aggregations of conspecifics [23,24], and it sometimes plays a role in male-male rivalry [25,26] or female-female rivalry [27]. Rivalry or aggressive behavior has not yet been observed in psyllids [28].

The effects of multiple nearby conspecifics on $D$. citri vibrational communication remain largely unexplored as, until now, interactions between duetting pairs of males and females alone on a tree have been a primary focus of study [16-18]. In single-pair studies, mating occurs primarily between the hours of 10:00 and 15:00 under natural light conditions but has been reported to occur at low rates from near sunrise until shortly after sunset [16-18,29]. A few recordings of multiple $D$. citri pairs have been collected from infested trees in field environments [30], but no experiments continuously recording calls over the full range of daylight hours have been reported. To investigate whether vibrational call activity [17] is differentially affected by increased numbers of nearby conspecifics, a study was conducted to compare the rates of calls/psyllid/h from 5 D. citri of each sex with the rates from 25 of each sex beginning at dawn after their release the previous afternoon onto one of two small trees of similar size and flush characteristics.

\section{Materials and Methods}

\subsection{Bioassay Arena}

Tests were conducted in a 200 by 200 by $206 \mathrm{~cm}$ bioassay chamber shielded by carpeting and acoustic foam for protection against sound and vibration interference. Two $10 \mathrm{~cm}$ square $\left(575 \mathrm{~cm}^{3}\right)$ pots-each containing a small Citrus macrophylla Wester (Sapindales: Rutaceae) tree, of approximately $15 \mathrm{~cm}$ in length-were selected from a greenhouse at the Center for Medical, Agricultural, and Veterinary Entomology (CMAVE), Gainesville, FL 32608, USA. Each tree was pruned regularly to stimulate production of ten flush shoots. One day before testing, each potted tree was placed on a metal stand on the floor of a 34 by 34 by $61 \mathrm{~cm}$ nylon-mesh bug dorm (Model 1466BV, BioQuip, Rancho Dominguez, CA, USA) sitting on a rack in the bioassay chamber. Light was provided by two 42 W LED panels (Model MXL-301, Utilitech, West Lawn, PA, USA), approximately $38 \mathrm{~cm}$ above the tops of the dorms, operating on a 14:10 light:dark cycle that began at 06:00.

\subsection{D. citri Handling Procedures: Treatments at $P_{5}$ and $P_{25}$ Densities}

On each of the 17 different test days, eighty mixed-age adult $D$. citri were aspirated from a colony in the CMAVE greenhouse [31], initiated before the 'Candidatus Liberibacter Asiaticus' bacteria causing huanglongbing was introduced into Florida and tested periodically for its continued absence [29]. They were chilled for $1 \mathrm{~min}$ in a freezer and sexed under a dissecting microscope. Five sexed adults each were placed in 12 petri dishes of the same sex. At 17:00, one dish with 5 males and one with 5 females were placed on the floor of the dorm designated as the $P_{5}$ treatment and the remaining dishes with a total of 25 males and 25 females were placed on the floor of the dorm designated as the $P_{25}$ treatment. Vibrational and video recording began at 06:00 the next morning. The surviving D. citri were removed and discarded on the day after recording after their locations and aggregational distributions were noted. The trees were rinsed with water, air-dried in the greenhouse, and pruned as needed before subsequent tests. The bug dorms were frozen and wiped down to eliminate insects, debris, and surface contamination before reuse. Treatments were rotated between trees after each 
test and the tree positions were rotated after each pair of tests to mitigate potential effects of tree and position within the chamber on $D$. citri behavior.

\subsection{Recording Procedures: Treatments at $P_{5}$ and $P_{25}$ Densities}

To record D. citri vibrational calls and incidental movements, an accelerometer (Model 352A24 PCB Piezotronics, PCB Technologies Ltd., Depew, NY, USA) was attached with beeswax to the lower stem of each tree. The accelerometer cable was extended through the zipper opening of the bug dorm to an amplifier (Model 480EO9, PCB Technologies Ltd.) with $20 \mathrm{~dB}$ gain. The amplifier signal was fed to an audio recorder (Model PMD661, Marantz, Cumberland, RI, USA) which stored the signals on a 32-GB SD memory card for subsequent signal analyses. The digitization rate was $44.1 \mathrm{kHz}$ in 16-bit, mono format. Continuous recordings were collected from each tree between times of 06:00 and 22:00. The recordings were subdivided into $10 \mathrm{~min}$ segments to accommodate memory limitations of the desktop computer that processed the vibrational signals afterwards using Raven 1.5 (Cornell Laboratory of Ornithology, Ithaca, NY USA) [32]. Live visual observations were enabled by use of separate video camera recorders (model HDR-SR1, Sony Corp, New York, NY, USA) focused on each tree. The vibrational and video signals were fed to a monitor outside the bioassay chamber for observation without interference from incidental background noise.

The first stage of signal analysis involved visual and aural screening of each 10 min segment with Raven to identify potential intervals of calling as well as periods of movement or other background noise, including vibrations produced by the tree itself [33]. When listeners detected such intervals, the 10 min segment was further analyzed using an automated signal analysis program, DAVIS, described in (Mankin [34,35]), which searched consecutive digital samples of the recorded segment for signal pulses with magnitudes that rose above a specified background threshold, e.g., a wingbeat pulse (Figure 1). When the threshold was exceeded, DAVIS then entered a subroutine which examined a series of consecutive $5 \mathrm{~ms}$ sections, calculating a 512 sample spectrum centering on the peak amplitude of the section. The series continued until the peak magnitude failed to exceed the threshold for $200 \mathrm{~ms}$. The complete set of signal pulses between the first and last signal magnitude above threshold was labeled as a pulse train.

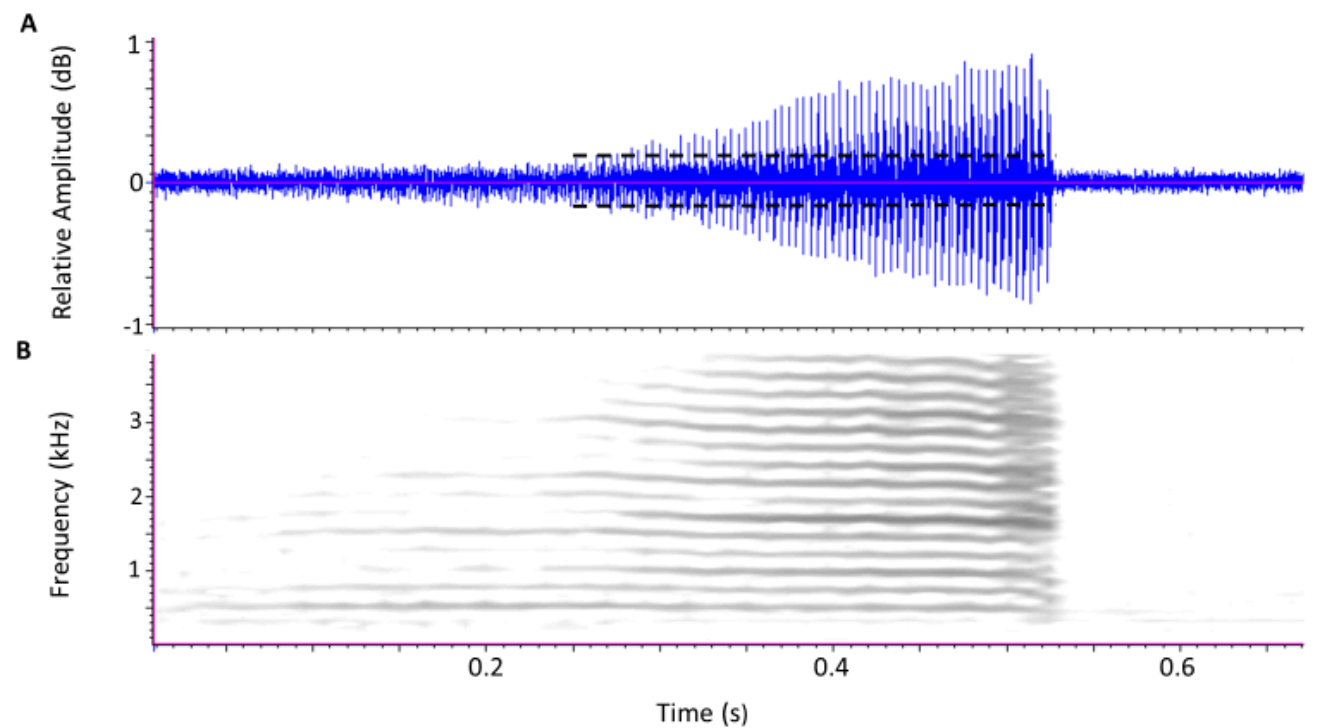

Figure 1. Oscillogram (A) and spectrogram (B) of a $0.28 \mathrm{~s}$, D. citri vibrational call. Dashed lines indicate the threshold amplitude for background noise, above which the signal analyzer program checks for the presence of wingbeat pulses. Darker shades in the spectrogram (1024 point spectrum width) indicate greater energy at the specified time and frequency. The ca. $250 \mathrm{~Hz}$ wingbeats appear as closely spaced signal pulses in the oscillogram and display multiple harmonics of $250 \mathrm{~Hz}$ in the spectrogram (1024 point spectrum width). 
Each spectrum in the resultant pulse train was least-squares matched with two spectral profiles [34] of known D. citri calls described previously in [16] (Figure 2). Spectra that matched well with either or both profiles were counted as potential sections of a call, and poor matches were classified as noise. DAVIS then passed through the recording again, classifying pulse trains as D. citri calls if they contained seven or more sections and at least $50 \%$ of the spectra in the train matched a D. citri profile. The spectra of the wingbeat pulses in Figure 1, for example, matched well with both spectral profiles in Figure 2, as can be seen in the close matchups between the frequencies of harmonic peaks in the spectrogram of Figure 1 and the frequencies of spectral peaks of the two profiles of Figure 2.

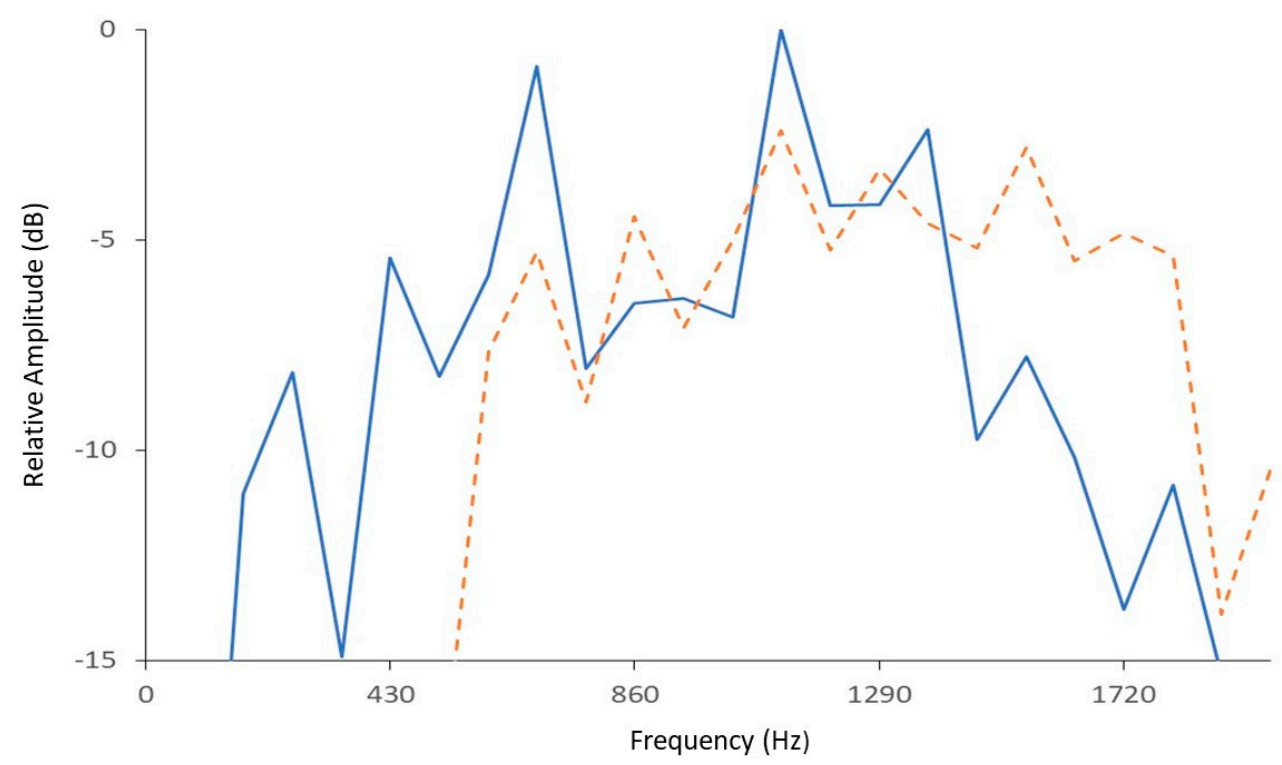

Figure 2. Profiles (mean spectra) of two representative vibrational calls (designated by solid and dashed lines) produced by $D$. citri on small citrus trees, recorded by methods described in Wenninger et al. [16]. The profiles were used to automate discrimination and counting of calls produced by $D$. citri in this study.

Other pulse trains that included insect movements or background noise, as in the example of Figure 3, were classified as non-calls. In general, as in Figure 3, the non-call pulse trains were much shorter in duration than D. citri calls. The beginning and ending times of both calls and non-calls were saved in a spreadsheet. Non-calls were further distinguished by listener assessment as either insect movement or other background noise. The counts of calls obtained from the $10 \mathrm{~min}$ segments were then summed over $1 \mathrm{~h}$ periods to obtain the numbers of calls per hour. The recording period was subdivided into four different calling period intervals based on differences in $D$. citri behavior at different times of day after sunrise (06:00). The intervals were designated as (1) sunrise: 06:00-10:00, (2) mating hours: 10:00-16:00, (3) evening: 16:00-20:00, and (4) darkness: 20:00-22:00. 
A

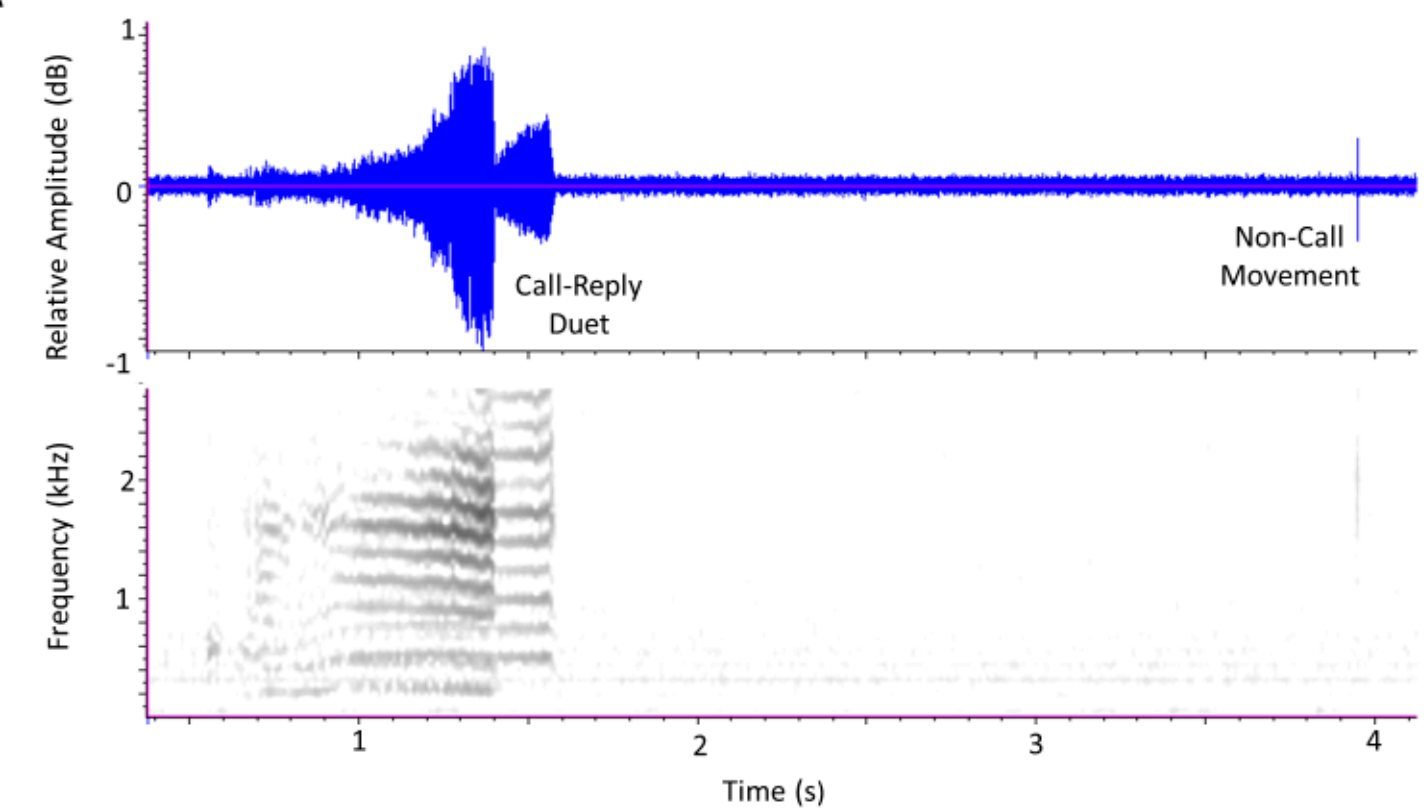

Figure 3. Oscillogram (A) and spectrogram (B) of a $4 \mathrm{~s}$ interval containing a Diaphorina citri call-reply duet and a non-call movement vibration. The spectra in the call-reply pulse train matched the D. citri profiles in Figure 2 but the spectra in the non-call pulse train failed to match either profile, and the pulse train was classified as a non-call movement.

\subsection{D. citri Handling Procedures: Flush Shoot Aggregation Sex Ratio Tests}

During the density treatments study, it was noted that psyllids were frequently aggregated in groups of four or more on flush shoots when they were removed from the trees at the end of each trial, approximately $40 \mathrm{~h}$ after the ACP were released onto the tree (Figure 4). The aggregations occurred more frequently on young than mature flush. This led to questions about potential interactions of males and females together on the same flush shoots that might lead to reductions in calling rates during mating hours. Additional studies were then conducted to consider the distributions of females and males in aggregations on young and mature flush.

Nine tests were conducted by releasing 25 psyllids of each sex into a bug dorm containing a small tree in the bioassay arena. Each test used the tree pruning procedure and the same release times and light cycle as in Section 2.1. On the morning of the second day, approximately $40 \mathrm{~h}$ after the insects were released, a flush shoot containing an aggregation of at least 4 psyllids was transferred into a vial, chilled for $1 \mathrm{~min}$ in a freezer, and sexed under a dissecting microscope. The counts for each aggregation were tabulated. 


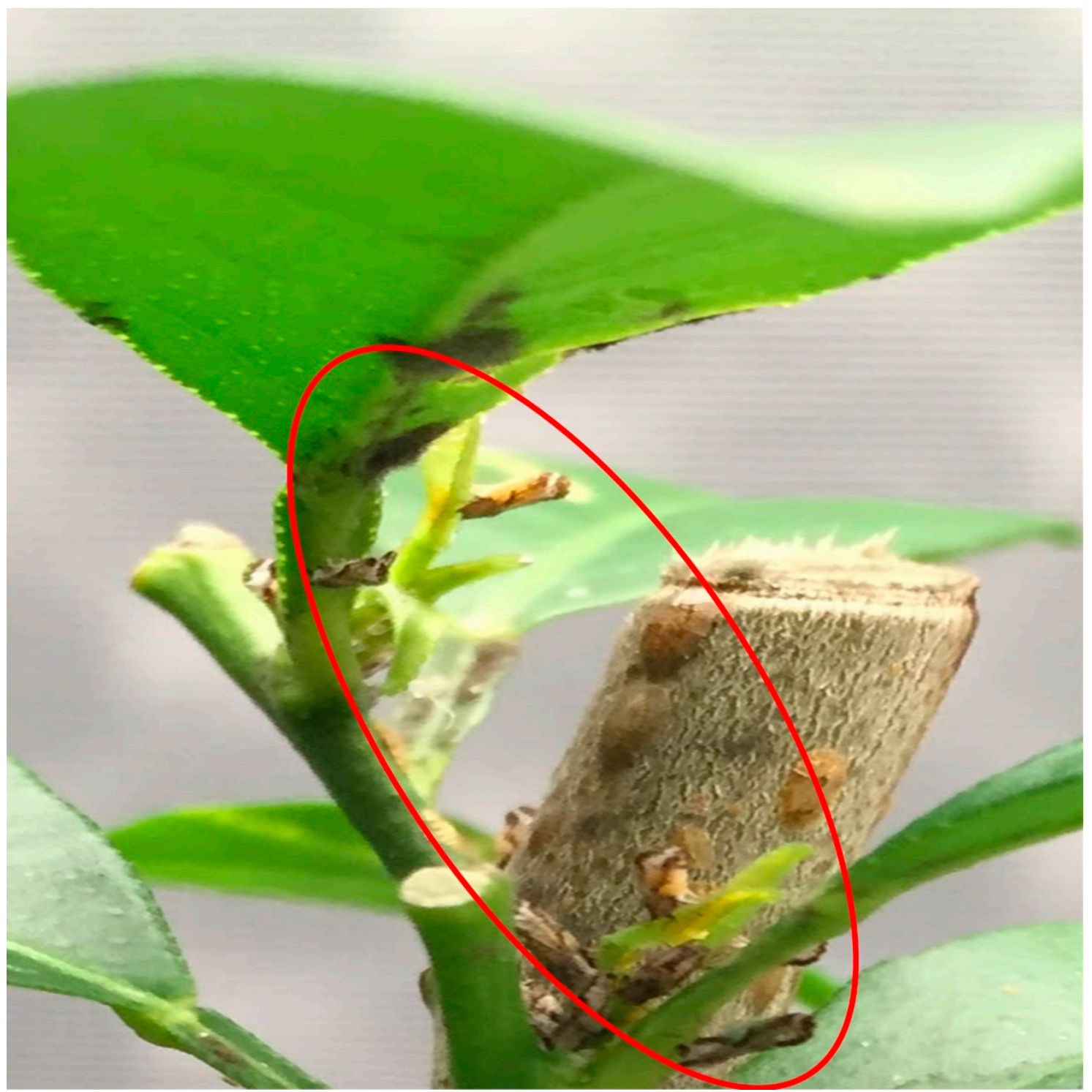

Figure 4. Example of multiple psyllids (circled) aggregating on young flush shoots at the end of a density treatment trial.

\subsection{D. citri Handling Procedures: Flush Age Tests}

Ten tests were conducted similarly to those in Section 2.4 except that, at the end of each test, all flush shoots containing aggregations of four or more psyllids were placed into vials. The psyllids were chilled for $1 \mathrm{~min}$ in a freezer and sexed under a dissecting microscope, and the dimensions of the flush materials were measured on a millimeter-scaled grid to estimate the surface area of the plant matter on which the aggregation occurred. The flush then was divided into two groups based on size: young flush with leaf surface area $<2.5 \mathrm{~cm}^{2}$ and mature flush with area $>2.5 \mathrm{~cm}^{2}$. The category of young flush corresponded approximately to categories SI and SII in [12], and categories V1-V3 in [36]. The areal density of females and males per flush shoot was calculated as the number of females and males in the aggregation divided by the estimated surface area in $\mathrm{cm}^{2}$.

\subsection{Statistical Analyses}

Shapiro-Wilk tests (Univariate Procedure, SAS Version 9.4 [37]) were performed to determine the normality of the distributions of call rates (calls/psyllid/h) used for analyses of the $P_{5}$ and $P_{25}$ psyllid density treatments over time. Because the distributions were found not to be normal $(N=68, W=0.646$, 
$p<0.001$ for the $P_{5}$ tests, and $\mathrm{N}=68, \mathrm{~W}=0.379, p<0.001$ for the $\mathrm{P}_{25}$ tests), the rates were transformed as $\log 10$ (rate+1). A sphericity test was conducted using Proc GLM [37] ( $\mathrm{df}=5$, Mauchly's Criterion $=0.887, \chi^{2}=3.70, p=0.594$ ), which indicated the variances of the differences between transformed call rates for all possible pairs of days were not significantly different, enabling repeated measures analysis of variance of call rates to be conducted (Table 1). A Tukey Honest Significant Difference (HSD) test [37] was conducted for comparisons between $P_{5}$ and $P_{25}$ calling rates during different calling period intervals.

Table 1. Repeated measures analysis of variance for psyllid density, calling period intervals, and interaction between calling period interval and density in $P_{5}$ and $P_{25}$ psyllid density treatments.

\begin{tabular}{lcccc}
\hline \multicolumn{1}{c}{ Source } & df & Mean Square & $\boldsymbol{F}$ & $\boldsymbol{p}$ \\
\hline Psyllid density & 1 & 0.224 & 5.06 & $0.031^{*}$ \\
Calling period interval & 3 & 0.172 & 4.76 & $0.039^{*}$ \\
Interval-density interaction & 3 & 0.036 & 1.00 & 0.390 \\
\hline
\end{tabular}

$F$ value is significant at the ${ }^{*} p<0.05$ level.

Differences in the occurrence of calls during different calling period intervals in the $P_{5}$ and $P_{25}$ density treatments were compared by enumerating the numbers of test days in which calls were detected during a specified calling period interval. Counts of the numbers of days in which calls were detected in the sunrise, mating period, evening, and darkness intervals during the 17 days of testing were compared between treatments by $\chi^{2}$ tests.

Shapiro-Wilk tests were conducted to determine the normality of the distributions of females and males counted on flush samples and the normality of the distributions of female and male densities on young and mature flush. Based on the results, a Student's $t$ test was conducted to compare the distributions of female and male counts, and a non-parametric Mann-Whitney U test was used to compare the mean densities of females and males on young and mature flush.

\section{Results}

\subsection{Calls and Movement Vibrations in Treatments at $P_{5}$ and $P_{25}$ Densities}

Vibrational calls occurred in all 17 days of testing, in addition to vibrations with spectral and temporal features like those documented as crawling or scraping in previous studies [38]. Loud buzzing and jumps from the tree occurred in several tests. The frequent occurrence of crawling and scraping movements was confirmed by inspection of the video recordings, which showed additional movements that were too weak to be detected as vibrations by the accelerometer. For this reason, we did not quantify the numbers of movement vibrations, but considered them an indication that the psyllids frequently walked along the branches during both lights-on and light-off cycles.

\subsection{Calling Rates in Treatments at $P_{5}$ and $P_{25}$ Densities}

The rates of vibrational calls varied considerably over time in both treatments, with the highest rates occurring during sunrise, mating hours, and evening intervals but few during darkness (Figure 5). 


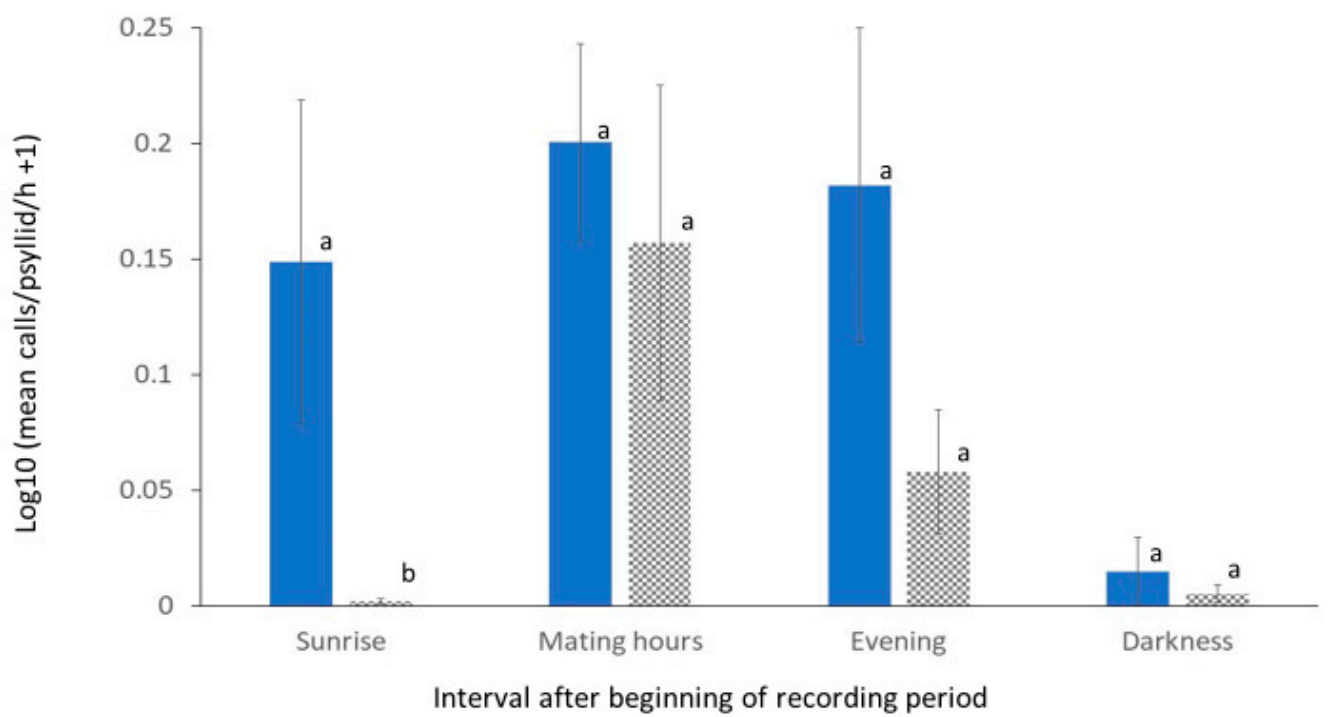

Figure 5. Log10-transformed means and standard errors (SEs) of the number of vibrational calls/psyllid/h detected over time after sunrise in tests with 5 (solid bar) or 25 (checkered bar) D. citri female and males released onto small citrus trees. Interval time periods were sunrise: 06-10:00, mating hours: 10-16:00, evening: 16-20:00, and darkness: 20-22:00. The SE are marked by capped-lines. Call rates in each recording period interval marked with the same letter are not significantly different $(p>0.05$ in a Tukey HSD test).

Analysis of variance of calling rates indicated statistically significant effects of psyllid density treatment and calling period intervals, but not the interaction between density and calling period interval (Table 1). The differences were not statistically significant except during the sunrise calling interval—during which, the calling rate was significantly greater for the $P_{5}$ than the $P_{25}$ treatment. There was no significant effect of density on the rates of calling during mating hours at the tested levels of population density.

Overall, 58 of the 142810 min periods in the experiment contained calls in the $P_{5}$ treatments, and 26 contained calls in the $P_{25}$ treatments. The numbers of test days with calls were not significantly different between treatments except in the sunrise calling period interval, where 8 days contained calls at in the $P_{5}$ treatment and 2 in the $P_{25}$ treatment $\left(\mathrm{df}=1, \chi^{2}=5.10, p=0.029\right)$. A mean of 8 psyllids were retrieved from the trees at the end of each test in the $P_{5}$ treatments and 34 in the $P_{25}$ treatments.

\subsection{Distributions of Females and Males in Flush Aggregations}

A mean of $4.8 \pm 2.49$ standard error (SE) females per aggregation sample and $2.6 \pm 1.33$ males were obtained in tests to consider the sex ratio in psyllid aggregations, a female to male ratio of 1.8. Because a Shapiro-Wilk test had indicated that the distributions of counts were not significantly different from normal (female $\mathrm{W}=0.90, \mathrm{n}=9, p=0.24$; male $\mathrm{W}=0.88, \mathrm{n}=9, p=0.15$ ), a Student's $\mathrm{t}$ test was conducted, which found that the mean number of females per aggregation was significantly different from the mean for males $(p=0.019)$.

In tests comparing the numbers of psyllids per unit surface area (areal density) on young and mature flush, a Shapiro-Wilk test indicated that the counts were not distributed normally for either females $(\mathrm{W}=0.925, \mathrm{n}=39, p=0.013$ ) or males $(\mathrm{W}=0.92, \mathrm{n}=39, p=0.009)$. Likewise, the Shapiro-Wilk test indicated that the areal densities were not distributed normally for either females $(\mathrm{W}=0.777$, $\mathrm{n}=33, p<0.001$ ) or males ( $\mathrm{W}=0.841, \mathrm{~N}=33, p<0.001)$. The mean density for both females and males on young flush was significantly greater than on mature flush (Table 2). However, although the density of females was higher than that of the males on young flush (Score $=80.5, \mathrm{U}=-1.81, p=0.07$ ) and mature flush (Score $=568.5, \mathrm{U}=0.60, p=0.55)$, the differences between densities of females and males 
on each flush type were not statistically significant. It should also be noted that, overall, $56 \%$ of psyllids released in the flush age treatments were retrieved in aggregations containing four or more psyllids.

Table 2. Mean \pm SE of female and male $D$. citri areal densities on young and mature flush.

\begin{tabular}{|c|c|c|c|c|c|}
\hline \multirow{3}{*}{ Sex } & \multicolumn{2}{|c|}{ Areal Density (No. psyllids/cm²) } & \multirow{3}{*}{ Score } & \multirow{3}{*}{$\mathbf{U}$} & \multirow{3}{*}{$p$} \\
\hline & On Fl & Гуре & & & \\
\hline & Young $(n=12)$ & Mature $(n=23)$ & & & \\
\hline Female & $2.72 \pm 0.42$ & $0.41 \pm 0.07$ & 280 & 4.29 & $<0.0001$ \\
\hline Male & $1.60 \pm 0.29$ & $0.47 \pm 0.08$ & 252 & 3.19 & 0.0013 \\
\hline
\end{tabular}

\section{Discussion}

The results indicate that the density of $D$. citri populations on host citrus trees affects the timing and rates of their duetting call behaviors. The distribution of call rates in Figure 5 is consistent with previous reports [22,29] that calling frequently occurs among single pairs between 10:00 and 15:00, but this study documents additionally that calling can occur between sunrise (06:00) and 10:00, particularly at the lower, $P_{5}$ density. A rationale for such a change in the pattern of calling in this context is suggested by considering that successful foraging on young flush, an ephemeral resource (with only approximately $18 \mathrm{~d}$ from bud swelling to maturity [36]), is a strong contributor to both female and male reproductive fitness [12]. Mating behavior [29] and foraging [4] both often occur on flush, and young flush is preferred by both sexes for foraging. Consequently, there is potential that calling behavior occurring outside of the peak mating period on trees with low-density D. citri populations can play a beneficial role not only to help locate mates but also to help both sexes locate preferred forage.

Diaphorina citri is known to respond strongly to visual cues when dispersing, and dispersal flights in field environments usually begin at approximately 10:00 [39]. While on a citrus host, however, if either sex is seeking to disperse to young flush because they have not detected it through visual or olfactory cues, calling by either a male or a female might elicit a reply from a female already present on young flush, which would assist the caller in locating a site of preference. Such behavior might explain the role of occasional calls by individual D. citri females in the absence of a duetting male [16]. The female may be calling primarily to obtain information about the location of nearby young flush. Although females usually do not move when they respond to males during duetting behavior, they have been observed to move in the context of foraging $[17,18]$. The finding that $56 \%$ of the psyllids released in the flush aggregation tests (Section 3.3) were found in aggregations on flush on the day after their release supports the possibility that calling by either female or male $D$. citri followed by movement towards the source of a reply might lead the caller to flush. Similar behaviors have been reported in other hemiptera $[23,24]$. Flush-seeking behaviors in D. citri are known to be density dependent, however. Diaphorina citri females show less preference to flush associated with odor from 10 or more females [15]. Density dependent effects might lead to reduced levels of calling to locate new foraging sites when females are present on a tree at high density. At low density, however, it could be beneficial to begin searching for flush on the host tree as soon as dawn, when it becomes possible to see a conspecific and the quality of the flush from which the conspecific has replied after a call.

Other instances have been observed where male insects that communicate through vibrational calls modify the spectrotemporal patterns of their calls in the physical presence of other males [40]. Thus, it is not completely unprecedented that density dependent effects might occur in different vibrational communication contexts and could contribute to the differences observed in this study between the $D$. citri calling rates at sunrise in the $P_{5}$ and $P_{25}$ density treatments. It remains to be determined whether calling outside of the mating hours interval is primarily by one sex and whether hunger or other physiological states also affect the likelihood that a psyllid will call.

Like the calling behaviors noted above that may be beneficial for both foraging and mating, call-fly behaviors previously identified by Hunt and Nault [41] also might lead male D. citri fortuitously to 
both a potential foraging site and a mating site after they have just migrated to a new tree. In previous reports where females and males at sampling sites have been counted, a slight preponderance of females has been found [42-44], which suggests that males would benefit by using calling behavior for either mate seeking or foraging. It is thus not surprising that mate-seeking calling behavior might evolve new roles or that individual $D$. citri in the presence of small numbers of conspecifics might behaviorally adapt through associative learning to call for help in locating preferred foraging sites [45-48]. Alternatively, a conspecific that would benefit from the presence of other conspecifics might call to recruit conspecifics [49].

Playback of hemipteran vibrational communication signals has been shown to trap males or have disruptive effects on mating success in multiple lab and field studies [19,27,30,50-57]. Thus, it may be worthwhile to consider the potential of vibrational signals that could disrupt foraging as well as mating in D. citri.

Finally, it has been suggested that reproductive fitness of $D$. citri is also affected by the presence of the Candidatus Liberibacter asiaticus bacterial agent that causes huanglongbing [58]; consequently, in field environments where the disease vector is present, the foraging and mating behavior might be influenced by the fraction of infected psyllids. Further studies are needed to resolve these and other unknowns about the mating and foraging interactions among female and male $D$. citri at different population densities.

\section{Conclusions}

This investigation about the effects of $D$. citri population density on vibrational communication signals and the formation of aggregations on citrus flush contributes to understanding $D$. citri female and male mating and foraging behaviors in different contexts. It also raises questions that suggest the need for additional study. As expected, calling occurred at the highest rates during the normal mating hours, independent of population density. However, calling occurred at significantly higher rates during the sunrise calling period at the $P_{5}$ density compared to the $P_{25}$ density. The known tendency of $D$. citri to aggregate on citrus flush $[5,21]$ was observed at both densities, suggesting that neither of the tested densities was sufficiently high to reduce the beneficial effects that aggregation on citrus flush has on reproductive fitness. In studies to consider aggregations on different kinds of flush, females were found to aggregate most densely on the youngest flush. Females were present at greater densities than males on young and mature flush, but the differences were not statistically significant. Efforts to co-opt forage- and mate-locating vibrational cues for D. citri management would likely benefit from further study of the density dependent behaviors observed in this exploratory report.

Author Contributions: Conceptualization, R.W.M., R.P., and M.G.; methodology, R.W.M., R.P., M.G., and E.J.; software, R.W.M.; validation, R.W.M. and M.G.; formal analysis, R.W.M. and E.J.; investigation, R.P. and M.G.; resources, R.W.M.; data curation, R.W.M.; writing-original draft preparation, R.W.M.; writing-review and editing, R.W.M., R.P., M.G., and E.J.; visualization, R.W.M.; supervision, R.W.M.; project administration, R.W.M.; funding acquisition, R.W.M. All authors have read and agreed to the published version of the manuscript.

Funding: This research was funded in part by a grant (No. 567) from the Citrus Research Development Foundation.

Acknowledgments: We thank Everett Foreman, Kayla Norton, and Julie Cantillo (USDA-ARS-CMAVE) for assistance in conducting and analyzing experiments. We thank James Colee (Statistical Consulting Unit, Institute of Food and Agricultural Sciences, University of Florida) for statistical assistance. Mention of a trademark or proprietary product is solely for the purpose of providing specific information and does not constitute a guarantee or warranty of the product by the USDA and does not imply its approval to the exclusion of other products that may also be suitable. The USDA is an equal opportunity employer.

Conflicts of Interest: The authors declare no conflict of interest. The funders had no role in the design of the study; in the collection, analyses, or interpretation of data; in the writing of the manuscript, or in the decision to publish the results. 


\section{References}

1. Hall, D.G.; Richardson, M.L.; Ammar, E.-D.; Halbert, S.E. Asian citrus psyllid, Diaphorina citri, vector of citrus huanglongbing disease. Entomol. Exp. Appl. 2012, 146, 207-223. [CrossRef]

2. Grafton-Cardwell, E.E.; Stelinski, L.L.; Stansly, P.A. Biology and management of Asian citrus psyllid, vector of the huanglongbing pathogens. Annu. Rev. Entomol. 2013, 58, 413-432. [CrossRef] [PubMed]

3. Wenninger, E.J.; Stelinski, L.L.; Hall, D.G. Roles of olfactory cues, visual cues, and mating status in orientation of Diaphorina citri Kuwayama (Hemiptera: Psyllidae) to four different host plants. Environ. Entomol. 2009, 38, 225-234. [CrossRef] [PubMed]

4. Martini, X.; Hoffman, M.; Coy, M.R.; Stelinski, L.L.; Pelz-Stelinski, K.S. Infection of an insect vector with a bacterial plant pathogen increases its propensity for dispersal. PLoS ONE 2015, 10, e0129373. [CrossRef] [PubMed]

5. Hall, D.G.; Albrigo, L.G. Estimating the relative abundance of flush shoots in citrus with implications on monitoring insects associated with flush. HortScience 2007, 42, 364-368. [CrossRef]

6. Sétamou, M.; Flores, D.; French, J.V.; Hall, D.G. Dispersion patterns and sampling plans for Diaphorina citri (Hemiptera: Psyllidae) in citrus. J. Econ. Entomol. 2008, 101, 1478-1487. [CrossRef]

7. Gottwald, T.R.; Da Graça, J.V.; Bassanezi, R.B. Citrus huanglongbing: The pathogen and its impact. Plant Health Prog. 2007. [CrossRef]

8. Pregmon, E.A.; Lujo, S.; Norton, K.; Hartman, E.; Rohde, B.; Zagvazdina, N.; Mankin, R.W. A “walker" tool to place Diaphorina citri (Hemiptera: Liviidae) adults at predetermined sites for bioassays of behavior in citrus (Sapindales: Rutaceae) trees. Fla. Entomol. 2016, 99, 308-310. [CrossRef]

9. Sétamou, M.; Sanchez, A.; Patt, J.M.; Nelson, S.D.; Jifon, J.; Louzada, E.S. Diurnal patterns of flight activity and effects of light on host finding behavior of the Asian citrus psyllid. J. Insect. Behav. 2012, 25, 264-276. [CrossRef]

10. Paris, T.M.; Allan, S.A.; Udell, B.J.; Stansly, P.A. Wavelength and polarization affect phototaxis of the Asian citrus psyllid. Insects 2017, 8, 88. [CrossRef]

11. Ammar, E.-D.; Hall, D.G.; Shatters, R.G., Jr. Stylet morphometrics and citrus leaf vein structure in relation to feeding behavior of the Asian citrus psyllid, Diaphorina citri, vector of citrus huanglongbing bacterium. PLOS ONE 2013, 8, e59914. [CrossRef]

12. Sétamou, M.; Simpson, C.R.; Alabi, O.J.; Nelson, S.D.; Telagamsetty, S.; Jifon, J.L. Quality matters: Influences of citrus flush physicochemical characteristics on population dynamics of the Asian citrus psyllid (Hemiptera: Liviidae). PLoS ONE 2016, 11, e0168997. [CrossRef] [PubMed]

13. Patt, J.M.; Sétamou, M. Responses of the Asian citrus psyllid to volatiles emitted by the flushing shoots of its rutaceous host plants. Environ. Entomol. 2010, 39, 618-624. [CrossRef] [PubMed]

14. Azam, M.; Jiang, Q.; Zhang, B.; Xu, C.; Chen, K. Citrus leaf volatiles as affected by developmental stage and genetic type. Int. J. Mol. Sci. 2013, 14, 17744-17766. [CrossRef] [PubMed]

15. Martini, X.; Kuhns, E.M.; Hoyte, A.; Stelinski, L.L. Plant volatiles and density-dependent conspecific female odors are used by Asian citrus psyllid to evaluate host suitability on a spatial scale. Arth. Plant Interact. 2014, 8, 453-460. [CrossRef]

16. Wenninger, E.J.; Hall, D.G.; Mankin, R.W. Vibrational communication between the sexes in Diaphorina citri (Hemiptera: Psyllidae). Ann. Entomol. Soc. Am. 2009, 102, 547-555. [CrossRef]

17. Zagvazdina, N.Y.; Paris, T.M.; Udell, B.J.; Stanislauskas, M.; McNeill, S.; Allan, S.A.; Mankin, R.W. Effects of atmospheric pressure trends on calling, mate-seeking, and phototaxis of Diaphorina citri (Hemiptera: Liviidae). Ann. Entomol. Soc. Am. 2015, 108, 762-770. [CrossRef]

18. Lujo, S.; Hartman, E.; Norton, K.; Pregmon, E.; Rohde, B.; Mankin, R.W. Disrupting mating behavior of Diaphorina citri (Liviidae). J. Econ. Entomol. 2016, 109, 2373-2379. [CrossRef]

19. Mann, R.S.; Rouseff, R.L.; Smoot, J.; Rao, N.; Meyer, W.L.; Lapointe, S.L.; Robbins, P.S.; Cha, D.; Linn, C.E.; Webster, F.X.; et al. Chemical and behavioral analysis of the cuticular hydrocarbons from Asian citrus psyllid, Diaphorina Citri. Insect Sci. 2013, 20, 367-378. [CrossRef]

20. Miklas, N.; Lasnier, T.; Renou, M. Male bugs modulate pheromone emission in response to vibratory signals from conspecifics. J. Chem. Ecol. 2003, 29, 561-574. [CrossRef]

21. Hall, D.G.; Hentz, M.G.; Patt, J.M. Behavioral assay on Asian citrus psyllid attraction to orange jasmine. J. Insect Behav. 2015, 28, 555-568. [CrossRef] 
22. Rohde, B.; Paris, T.M.; Heatherington, E.M.; Hall, D.G.; Mankin, R.W. Responses of Diaphorina citri (Hemiptera: Psyllidae) to conspecific vibrational signals and synthetic mimics. Ann. Entomol. Soc. Am. 2013, 106, 392-399. [CrossRef]

23. Cocroft, R.B. Vibrational communication and the ecology of group-living herbivorous insects. Am. Zool. 2001, 41, 1215-1221. [CrossRef]

24. Cocroft, R.B. Vibrational communication facilitates cooperative foraging in a phloem-feeding insect. Proc. Roy. Soc. B Biol. Sci. 2005, 272, 1023-1029. [CrossRef]

25. Mazzoni, V.; Prešern, J.; Lucchi, A.; Virant-Doberlet, M. Reproductive strategy of the Nearctic leafhopper Scaphoideus titanus Ball (Hemiptera: Cicadellidae). Bull. Entomol. Res. 2009, 99, 401-413. [CrossRef]

26. Ahmed, A.M.; Muhamad, R.; Omar, D.; Majid, D.L.; Gnanasegaram, M. Influence of male age on producing rival calls in brown planthopper Nilaparvata lugens Stål (Homoptera: Delphacidae). J. Entomol. Zool. Stud. 2016, 4, 163-166.

27. Čokl, A.; Kosi, A.Z.; Laumann, R.A.; Virant-Doberlet, M. Female competition for availability of males in insects: The Nezara viridula (Linnaeus, 1758) model. Insect Sci. 2019. [CrossRef]

28. Tishechkin, D.Y. Vibratory communication in Psylloidea (Hemiptera). In Insect Sounds and Communication: Physiology, Behavior, Ecology, and Evolution; Drosopoulos, S., Claridge, M.F., Eds.; CRC Press: New York, NY, USA, 2005; pp. 357-363.

29. Wenninger, E.J.; Hall, D.G. Daily timing of mating and age at reproductive maturity in Diaphorina citri (Hemiptera: Psyllidae). Fla. Entomol. 2007, 90, 715-722. [CrossRef]

30. Mankin, R.W.; Rohde, B.; McNeill, S. Vibrational duetting mimics to trap and disrupt mating of the devastating Asian citrus psyllid insect pest. Proc. Meet. Acoust. 2016, 25, 010006.

31. Paris, T.M.; Rohde, B.B.; Allan, S.A.; Mankin, R.W.; Stansly, P.A. Synchronized rearing of mated and unmated Diaphorina citri (Hemiptera: Liviidae) of known age. Fla. Entomol. 2013, 96, 1631-1634. [CrossRef]

32. Charif, R.A.; Waack, A.M.; Strickman, L.M. Raven Pro 1.3 User's Manual; Cornell Laboratory of Ornithology: Ithaca, NY, USA, 2008.

33. Mankin, R.W.; Stanaland, D.; Haseeb, M.; Rohde, B.; Menocal, O.; Carrillo, D. Assessment of plant structural characteristics, health, and ecology using bioacoustic tools. Proc. Mtg. Acoust. 2018, 33, 010003.

34. Mankin, R.W.; Brandhorst-Hubbard, J.; Flanders, K.L.; Zhang, M.; Crocker, R.L.; Lapointe, S.L.; McCoy, C.W.; Fisher, J.R.; Weaver, D.K. Eavesdropping on insects hidden in soil and interior structures of plants. J. Econ. Entomol. 2000, 93, 1173-1182. [CrossRef]

35. Mankin, R.W.; Anderson, J.B.; Mizrach, A.; Epsky, N.D.; Shuman, D.; Heath, R.R.; Mazor, M.; Hetzroni, A.; Grinshpun, J.; Taylor, P.W.; et al. Broadcasts of wingfanning vibrations recorded from calling male Ceratitis capitata (Diptera: Tephritidae) increase captures of females in traps. J. Econ. Entomol. 2004, 97, 1299-1309. [CrossRef]

36. Cifuentes-Arenas, J.C.; de Goes, A.; de Miranda, M.P.; Beattie, G.A.C.; Lopes, S.A. Citrus flush shoot ontogeny modulates biotic potential of Diaphorina citri. PLoS ONE 2018, 13, e0190563. [CrossRef]

37. SAS Institute Inc. Base SAS 9.4 Procedures Guide, Statistical Procedures, 2nd ed.; SAS Institute Inc.: Cary, NC, USA, 2013.

38. Mankin, R.W.; Hodges, R.D.; Schal, C.; Pereira, R.M.; Koehler, P.G. Acoustic indicators for targeted detection of stored product and urban insect pests by inexpensive infrared, acoustic, and vibrational detection of movement. J. Econ. Entomol. 2010, 103, 1135-1143. [CrossRef]

39. Paris, T.M.; Croxton, S.D.; Stansly, P.A.; Allan, S.A. Temporal response and attraction of Diaphorina citri to visual stimuli. Ent. Exp. Appl. 2015, 155, 137-147. [CrossRef]

40. Bedoya, C.L.; Brockerhoff, E.G.; Hayes, M.; Pawson, S.M.; Nanar-Rodriguez, A.; Nelson, X.J. Acoustic communication of the red-haired bark beetle Hylurgus ligniperda. Physiol. Entomol. 2019. [CrossRef]

41. Hunt, R.E.; Nault, L.R. Roles of interplant movement, acoustic communication and phototaxis in mate-location of the leafhopper Graminella nigrifrons. Beh. Ecol. Sociobiol. 1991, 28, 315-320. [CrossRef]

42. Catling, H.D. Distribution of the psyllid vectors of citrus greening disease, with notes on the biology and bionomics of Diaphorina citri. FAO Plant Protect. Bull. 1970, 18, 8-15.

43. Pande, Y.D. Biology of citrus psylla, Diaphorina citri Kuw. (Hemiptera: Psyllidae). Isr. J. Entomol. 1971, 6, 307-311.

44. Alves, G.R.; Diniz, A.J.F.; Parra, J.R.P. Biology of the huanglongbing vector Diaphorina citri (Hemiptera: Liviidae) on different host plants. J. Econ. Entomol. 2014, 107, 691-696. [CrossRef] [PubMed] 
45. Patt, J.M.; Stockton, D.; Meikle, W.G.; Sétamou, M.; Mafra-Neto, A.; Adamczyk, J.J. Innate and conditioned responses to chemosensory and visual cues in asian citrus psyllid, Diaphorina citri (Hemiptera: Liviidae), vector of huanglongbing pathogens. Insects 2014, 5, 921-941. [CrossRef] [PubMed]

46. Stockton, D.G.; Martini, X.; Stelinski, L.L. Male psyllids differentially learn in the context of copulation. Insects 2017, 8, 16. [CrossRef] [PubMed]

47. Stockton, D.G.; Pescitelli, L.E.; Martini, X.; Stelinski, L.L. Female mate preference in an invasive phytopathogen vector: How learning may influence mate choice and fecundity in Diaphorina citri. Entomol. Exp. Appl. 2017, 164, 16-26. [CrossRef]

48. Li, X.; Ishimoto, H.; Kamikouchi, A. Auditory experience controls the maturation of song discrimination and sexual response in Drosophila. eLife 2018, 7, e34348. [CrossRef] [PubMed]

49. Yadav, C.; Guedes, R.N.C.; Matheson, S.M.; Timbers, T.A.; Yack, J.E. Invitation by vibration: Recruitment to feeding shelters in social caterpillars. Behav. Ecol. Sociobiol. 2017, 71, 51. [CrossRef]

50. Čokl, A.A.; Millar, J.G. Manipulation of insect signaling for monitoring and control of insect pests. In Biorational Control of Arthropod Pests; Ishaaya, I., Horowitz, A.R., Eds.; Springer: Berlin/Heidelberg, Germany, 2009; pp. 279-316.

51. Hofstetter, R.W.; Dunn, D.D.; McGuire, R.; Potter, K.A. Using acoustic technology to reduce bark beetle reproduction. Pest Manag. Sci. 2014, 70, 24-27. [CrossRef]

52. Polajnar, J.; Eriksson, A.; Lucchi, A.; Anfora, G.; Virant-Doberlet, M.; Mazzoni, V. Manipulating behaviour with substrate-borne vibrations-potential for insect pest control. Pest Manag. Sci. 2016, 71, 15-23. [CrossRef]

53. Mazzoni, V.; Polajnar, J.; Baldini, M.; Rossi Stacconi, M.V.; Anfora, G.; Guidetti, R.; Maistrello, L. Use of substrate-borne vibrational signals to attract the brown marmorated stink bug, Halyomorpha halys. J. Pest. Sci. 2017, 90, 1219-1229. [CrossRef]

54. Nieri, R.; Mazzoni, V.; Gordon, S.D.; Krugner, R. Mating behavior and vibrational mimicry in the glassy-winged sharpshooter, Homalodisca vitripennis. J. Pest Sci. 2017, 90, 887-899. [CrossRef]

55. Mazzoni, V.; Gordon, S.D.; Nieri, R.; Krugner, R. Design of a candidate vibrational signal for mating disruption against the glassy-winged sharpshooter, Homalodisca vitripennis. Pest Man. Sci. 2017, 73, 2328-2333. [CrossRef] [PubMed]

56. Nieri, R.; Mazzoni, V. Vibrational mating disruption of Empoasca vitis by natural or artificial disturbance noises. Pest Man. Sci. 2019, 75, 1065-1073. [CrossRef]

57. Gordon, S.D.; Sandoval, N.; Mazzoni, V.; Krugner, R. Mating interference of glassy-winged sharpshooters, Homalodisca vitripennis. Entomol. Exp. Appl. 2017, 164, 27-34. [CrossRef]

58. Pelz-Stelinski, K.S.; Killiny, N. Better together: Association with 'Candidatus Liberibacter Asiaticus' increases the reproductive fitness of its insect vector, Diaphorina citri (Hemiptera: Liviidae). Ann. Entomol. Soc. Am. 2016, 109, 371-376. [CrossRef] [PubMed]

(C) 2020 by the authors. Licensee MDPI, Basel, Switzerland. This article is an open access article distributed under the terms and conditions of the Creative Commons Attribution (CC BY) license (http://creativecommons.org/licenses/by/4.0/). 